\title{
$\therefore$ A Study on the Potential of Cabbage Extract against Snake-venom
}

\author{
IJCRR \\ Section: Healthcare \\ ISI Impact Factor \\ (2019-20): 1.628 \\ IC Value (2019): 90.81 \\ SJIF (2020) $=7.893$

\section{Ballal Suhas, Bajaj Deepti}

Department of Chemistry, School of Science B-2, JAIN (Deemed-to-be University), Bangalore, India.

\section{ABSTRACT}

Introduction: Snake venom causes mortality and tissue disfiguration among the rural folks. Though anti-dote or anti-snake venom serum is freely available at government health care centres yet is marred by inept handling, storage and lack of specificity. In India, most of the venomous snakes belong to the Elapidae\&Viperidae families.

Aim: The need of the hour is to discover new anti-dotes which are not only cheap but can act against a wide range of snake venoms. In this paper, the venom of the Flavanoids has been reported to have anti-snake venom activity due to which the cabbage (Brassica oleracea) was selected for its high flavonoid content.

Methodology: The leafy body of Brassica oleracea var capitata (family: Brassicaceae) was chosen to be studied as a source of anti-dote against the venom of Russell's viper (Daboiarusselii). The leaves were used to prepare an extract which was tested for having the potential to reduce proteolysis in plasma cells in presence of the venom.

Results: The effective concentration 50 (EC50) of Russell's viper (Daboiarusselii) was determined on goat's plasma at 4.54 $\mathrm{micron} / \mathrm{mL}$ and the aqueous extract of cabbage was seen to prevent proteolysis. Next, the minimum coagulant dose (MCD) was calculated at $3.69 \mu \mathrm{g} / \mathrm{ml}$ for goat's plasma and the aqueous extract of cabbage was seen to delay venom induced plasma clotting.

Conclusion: An analysis of these results indicate that cabbage can be a potential source of extract capable of reducing physiological effects caused by snake venom.

Key Words: Antidote or Anti-snake venom, Clotting time, Daboiarusselli (Russel Viper), Effective concentration, Goat's plasma, Minimum coagulant dose (MCD), Proteolysis

\section{INTRODUCTION}

In most rural parts of the world, death or disfiguration of body parts due to untreated cases of snake bites is a common occupational hazard. The major reason for this is poor rural healthcare facilities, delay in the administration of the antisnake venom, non-specificity of the anti-snake venom (AVS) towards that particular type of snake venom. In India, more than 2 lakhs of snake bite out of which more than 35,000 cases are said to be fatal annually. However, most of these cases are calculated arbitrarily as not only are these cases under-reported but most of the cases are referred to traditional healers. ${ }^{1,2,3}$

Out of 3000 known species of snakes, 300 are known to be venomous. In India, there are nearly 53 species of venomous snakes out of 216 species of reported species of snakes. In
India, venomous snakes are of mainly Elapidae and Viperidae families comprising members such the Echiscarinatus of the saw-scaled viper, Daboiarusselii or Russell's viper, Bungaruscaeruleus or the common krait, Najanaja or the Indian spectacled cobra. From the southern parts of India, Hypnalehypnale and $H$. Nepa both as Hump-nosed pit vipers have been reported. ${ }^{1,4-7}$ Snake venoms have enzymes like metalloproteases, serine proteases, phospholipases A2, etc\& the snake envenomation's pathophysiology involves a multistep series of occurrences depending upon the synergistic actions of the components of the venom. . $^{8,9,10}$

\section{Anti-snake venom and its limitations}

Regarding management of snake venoms, anti-venoms consisting of fragments of antibodies or antibodies are first harvested and isolated from large mammals' plasma (horses,

\section{Corresponding Author:}

Ballal Suhas, Department of Chemistry, School of Science B-2, JAIN (Deemed-to-be University), Bangalore, India. Phone: 9899806910; Email: publicationeip@gmail.com
ISSN: 2231-2196 (Print)
ISSN: 0975-5241 (Online)

Received: 22.01 .2021

Revised: 03.04 .2021

Accepted: 30.05 .2021

Published: 01.12 .2021 
sheep etc.). For this these mammals have been pre-immunized with non-fatal doses of the snake venom. Following isolation, the anti-venom is administered intravenously to the victim of envenomation. Anti-snake venom or anti-dote therapy is based on the principle that they bind to \& neutralize snake venom. ${ }^{4,11,12}$

However, the anti-dote therapy is itself marred by certain drawbacks, such as pyrogenic \& anaphylactic reactions including chills, tachycardia etc.

- Inability to protect against immediate local tissue damage; - Anti-dole's inability to be effective against venoms separated by geography $\bullet$ Improper storage \& use of the anti-dote.

Even more, are the problems regarding the manufacture of the snake anti-venom or anti-dote are due to the following: ${ }^{5}$

- The lack of stability in the anti-dote market;

- Low-profit margins in the selling of anti-dote;

- Lack of data on the distribution and number of doses of anti-dote required.

In this regard, various investigators have reported novel phytochemicals having anti-snake venom properties some of which have been summarized in Table $1 \& 2$. Moreover, many flavonoids have been reported to have anti-snake venom activity and as Cabbage (Brassica oleracea) is rich in flavonoids thereby it has been investigated for its anti-snake venom activity. ${ }^{13,14,15}$

\section{LITERATURE REVIEW}

Brassica oleracea includes several cultivars such as Cauliflower, Cabbages etc. It is especially rich in flavonoids and glucosinolates. All these including phenolic compounds are to play a protective role against ultraviolet radiation and also protects against the deleterious activities of Reactant Oxygen Species (ROS) as tabulated under Table 3 and $4 .{ }^{16,17,18}$

\section{RESEARCH QUESTIONS}

Though anti-dote towards snake envenomation is available at the primary health centres yet it does not only cause hypersensitivity reactions but also is not always specific towards all types of snake venom. Of late many phytochemicals including flavonoids have been reported to have snake antidote properties, hence this paper has attempted to evaluate the snake venom anti-dote property of the aqueous extract of cabbage leaves as they are rich in flavonoids and are available easily.

\section{MATERIALS AND METHOD}

\section{Experimental Design}

Firstly, snake venom, a commercial anti-dote or anti-venom and goat's blood from where the plasma would be separated would be collected, following which cabbage leaves would be procured from the market. Then the effectiveness of the aqueous extract of cabbage would be tested upon its ability for its anti-proteolysis activity, anti-hemolytic activity and anti-clotting activity.

\section{Reagents}

All reagents were of the best analytical grade.

\section{Venom}

Snake venom of Daboiarusselli (Russel Viper) in a lyophilized state was sanctioned from the Alipur Zoo, Kolkata, India and was kept at $4{ }^{\circ} \mathrm{C}$ for further use. It was dissolved in $1 \%$ Phosphate Buffer Saline (PBS) and centrifuged for 10 min at $1000 \mathrm{rpm}$ and stored at $4^{\circ} \mathrm{C}$ until further use. Venom concentration was expressed in terms of dry weight.

\section{Snake Venom anti-dote}

Monovalent snake venom antidote in lyophilized form (for reference) was purchased from the Bengal chemicals in Kolkata was dissolved in $1 \%$ PBS.

\section{Botanical material}

The leafy body of Brassica oleracea var capitata (family: Brassicaceae) that was obtained from the local market was washed, dried $\left(50^{\circ} \mathrm{C}\right)$, grained and suspended in water to obtain an aqueous suspension. Following this, the suspensions were exposed to ultrasonication for 60 minutes, at $25^{\circ} \mathrm{C}$, to isolate its secondary metabolites. The aqueous extracts were filtered with a $0.22 \mu \mathrm{m}$ sterile membrane and lyophilized.

\section{Determination of Proteolytic Activity of Daboi- arusselli venom}

As per earlier publications, Daboiarusselli venom's proteolytic activity was determined using goat's plasma. ${ }^{19}$ Briefly, aliquots of Daboiarusselli venom $(0-100 \mathrm{micron} / \mathrm{mL})$ were incubated along with goat's plasma at $37^{\circ} \mathrm{C}$ for $100 \mathrm{~min}$ in a total volume of $1.5 \mathrm{~mL}$. An effective concentration $50\left(\mathrm{EC}_{50}\right)$ was denoted as the concentration of Daboiarusselli venom (micro/mL) that can induce $50 \%$ proteolysis.

Regarding the inhibitory experiments, an EC of Daboiarusselli venom (40.54 microg $/ \mathrm{mL}$ ) was incubated at room temperature separately with various amounts of the aqueous extracts of cabbage and commercial AVS to determine its proteolytic activity accordingly in goat's plasma. Positive 
control experiments were performed by incubating venom with PBS (1\% v/v).

\section{Clotting Activity}

Citrated normal goat plasma (diluted with an equal volume of PBS) was prepared accordingly and was mixed with Daboiarussellisnake venom (0-100 micron/mL) and the clotting time was monitored using an Amelungcoagulometer, model KC4A (Labcon). The concentration of venom (30.69 microg/ $\mathrm{mL}$ ) that clotted plasma in 60 seconds was considered as the minimum coagulant dose (MCD). To evaluate the inhibitory effect, the aqueous extracts of cabbage and the commercial anti-dote separately were kept at room temperature for 30 minutes with $1 \mathrm{MCD}$ of venom (30.69 micron/mL) and then the mixture was added to the plasma to record the clotting time as reported earlier. ${ }^{10}$

\section{Statistical Analysis}

${ }^{*} p$ values of $\leq 0.05$ were considered to be statistically significant as reported earlier. ${ }^{10}$

\section{RESULTS AND DISCUSSIONS}

The main objective of this paper is to identify whether the aqueous extract of cabbage can act as an antidote against snake venom. In this regard, the anti-proteolysis and prevention of venom-induced clotting both in goat's plasma was identified.

\section{Anti-Proteolysis role of the aqueous extract of cabbage:}

Goat's blood incubated with snake's venom yielded an effective concentration of $50\left(\mathrm{EC}_{50}\right)$ at $40.54 \mathrm{micron} / \mathrm{mL}$ after 100 mins. Keeping the $\mathrm{EC}_{50}$ value constant for the snake venom, the percentage inhibition of proteolysis of goat's blood in the presence of the aqueous extract of cabbage and the commercial anti-dote was observed with the cabbage extract preventing hemolysis more efficiently than the commercially available anti-dote (Figure 1).

\section{Prevention of venom induced clotting:}

Firstly, minimum coagulant dose (MCD) was calculated at $30.69 \mu \mathrm{g} / \mathrm{ml}$ for goat's plasma i.e. this amount coagulated the goat's plasma at $60 \mathrm{~s}$. Keeping this amount constant, the aqueous extracts of cabbage and the commercial anti-dote separately were kept at room temperature for 30 minutes with $1 \mathrm{MCD}$ of venom (30.69 micron/mL) and then the mixture was added to the plasma to record the clotting time. The aqueous extract of cabbage showed higher preventive action than the commercial anti-dote by increasing the clotting time as compared to the control set (Figure 2).

\section{CONCLUSION}

One of the neglected tropical diseases is Snakebite envenomation that every year kills and injures annually. Major Indian poisonous snakes belong to the families Elapidae (Cobras, Krait etc.) \&Viperidae (Vipers). Russell Viper (Daboiarusselli)'s venom was chosen in this paper as this snake's venom has hemotoxic activity. Moreover, there are reports of flavonoids having anti-snake venom activity; thereby the cabbage (Brassica oleracea) was chosen to check for its anti-snake venom activity. Firstly, snake venom and a polyvalent anti-venom serum or anti-dote were commercially procured. Next goat's plasma was also obtained. Daboiarusselli venom's proteolytic activity was determined using goat's plasma. Secondly, after calculating the minimum coagulant dose (MCD) the clotting time was recorded in presence of the aqueous extract of cabbage leaves.

Effective concentration $50\left(\mathrm{EC}_{50}\right)$ of the goat's blood was at $40.54 \mathrm{micron} / \mathrm{mL}$ after $100 \mathrm{mins}$. The cabbage extract prevented hemolysis more efficiently than the commercially available anti-dote. Secondly, the aqueous extract of cabbage showed higher preventive action than the commercial anti-dote by increasing the clotting time as compared to the control set.

As most of the rural population tend to flock to traditional healers who tend to patients of snake-bites with medicinal herbs, which tend to be rich in flavonoids thereby cabbage was chosen for its common vegetable status and also being rich in flavonoids. Thereby the humble cabbage maybe used for large scale production of anti-snake venom in the future.

\section{ACKNOWLEDGEMENT}

The authors acknowledge the immense help received from the scholars whose articles are cited and included in references to this manuscript. The authors are also grateful to authors/editors/publishers of all those articles, journals and books from where the literature for this article has been reviewed and discussed.

\section{Conflict of interest: Nil}

\section{Source of funding: Nil}

\section{Author contribution:}

All authors have contributed equally in data collection and writing the manuscript.

\section{REFERENCES}

1. Gupta YK, Peshin SS. Do herbal medicines have potential for managing snake bite envenomation? Toxicology International. 2012. 
2. Moolakkadath T, Aqil M, Ahad A, Imam SS, Iqbal B, Sultana Y, et al. Development of transethosomes formulation for dermal fisetin delivery: Box-Behnken design, optimization, in vitro skin penetration, vesicles-skin interaction and dermatokinetic studies. Artif Cells, Nanomedicine Biotechnol. 2018.

3. Kumar N, Prasad P, Jash E, Saini M, Husain A, Goldman A, et al. Insights into exchange factor directly activated by cAMP (EPAC) as a potential target for cancer treatment. Molecular and Cellular Biochemistry. 2018.

4. Sebastin Santhosh M, Hemshekhar M, Sunitha K, M. Thushara R, Jnaneshwari S, Kemparaju K, et al. Snake Venom Induced Local Toxicities: Plant Secondary Metabolites as an Auxiliary Therapy. Mini-Reviews Med Chem. 2012.

5. Ramarao N, Lereclus D, Sorokin A, Oh MH, Cox JM, Singh AKA, et al. Sample APA Papers: Literature Review. African J Biotechnol. 2011.

6. Alam MI. Inhibition of Toxic Effects of Viper and Cobra Venom by Indian Medicinal Plants. Pharmacol \&amp; Pharm. 2014;

7. Senji Laxme RR, Khochare S, de Souza HF, Ahuja B, Suranse V, Martin G, et al. Beyond the 'Big four': Venom profiling of the medically important yet neglected Indian snakes reveals disturbing antivenom deficiencies. PLoS Negl Trop Dis. 2019.

8. Afzal M, Kazmi I, Khan R, Rana P, Kumar V, Al-Abbasi FA, et al. Thiamine potentiates chemoprotective effects of ibuprofen in DEN induced hepatic cancer via alteration of oxidative stress and inflammatory mechanism. Arch Biochem Biophys. 2017.

9. Fakhria A, Gilani SJ, Imam SS, Chandrakala. Formulation of thymoquinone loaded chitosan nano vesicles: In-vitro evaluation and in-vivo anti-hyperlipidemic assessment. J Drug Deliv Sci Technol. 2019.

10. Saquib Hasnain M, Rishishwar P, Rishishwar S, Ali S, Nayak AK. Isolation and characterization of Linum usitatisimum polysaccharide to prepare mucoadhesive beads of diclofenac sodium. Int J Biol Macromol. 2018.
11. Uddin MS, Kabir MT, Mamun A Al, Barreto GE, Rashid M, Perveen A, et al. Pharmacological approaches to mitigate neuroinflammation in Alzheimer's disease. Int. Immunopharmacol. 2020.

12. Ameeduzzafar, Imam SS, Bukhari SNA, Ali A. Preparation and evaluation of novel chitosan: gelrite ocular system containing besifloxacin for topical treatment of bacterial conjunctivitis: scintigraphy, ocular irritation and retention assessment. Artif Cells, Nanomedicine Biotechnol. 2018.

13. Preciado LM, Comer J, Núñez V, Rey-Súarez P, Pereañez JA. Inhibition of a snake venom metalloproteinase by the flavonoid myricetin. Molecules. 2018.

14. Rahman M, Beg S, Verma A, Kazmi I, Patel DK, Anwar F, et al. Therapeutic Applications of Liposomal Based Drug Delivery and Drug Targeting for Immune Linked Inflammatory Maladies: A Contemporary View Point. Curr Drug Targets. 2017.

15. Uddin MS, Kabir MT, Jeandet P, Mathew B, Ashraf GM, Perveen A, et al. Novel anti-Alzheimer's therapeutic molecules targeting amyloid precursor protein processing. Oxidative Medicine and Cellular Longevity. 2020.

16. Mageney V, Neugart S, Albach DC. A guide to the variability of flavonoids in Brassica oleracea. Molecules. 2017.

17. Naguib AEMM, El-Baz FK, Salama ZA, Abd El Baky Hanaa $\mathrm{H}$, Ali HF, Gaafar AA. Enhancement of phenolics, flavonoids and glucosinolates of Broccoli (Brassica olaracea, var. Italica) as antioxidants in response to organic and bio-organic fertilizers. J Saudi Soc Agric Sci. 2012.

18. Valverde J, Reilly K, Villacreces S, Gaffney M, Grant J, Brunton $\mathrm{N}$. Variation in bioactive content in broccoli (Brassica oleracea var. Italica) grown under conventional and organic production systems. J Sci Food Agric. 2015.

19. De Oliveira EC, Fernandes CP, Sanchez EF, Rocha L, Fuly AL. Inhibitory effect of plant Manilkara subsericea against biological activities of Lachesis muta snake venom. Biomed Res Int. 2014.

Table 1: Phytochemicals originated from plants that are used against snake-bites. All these plants constitute phytochemicals that can be utilized as anti-snake venom anti-dotes.

\begin{tabular}{ll} 
Active principle & Plant \\
Amenth of lavone, Quercetin, Myricetin & Davillaeliptica, Mouriripusa, \\
Alkylamides, Ketoalkenes, Polysaccharides & Echinacea sp \\
Polyphenols & Pentaceburminica, Areca catechu \\
Ellagic acids & Caseariasylvestris \\
Edunol & Harpalycebrasiliana \\
Lupeolactate & Hemidesmusindicus \\
Cucurbitane glycosides, trichotetral & Trichosanthestricuspidata \\
ß-sitosterol, stigma sterol & Plucheaindica \\
Pthalates & Vitisnegundo \\
Tannins, steroids, Alkaloids & Delonixelata \\
Tannins & Guierasenegalensis \\
Quercetin & Aliumcepa \\
Resverotrol & Cissusassamica \\
Stigmasterol, D-mannitol & Ecliptica prostrate \\
Aristolochic acid & Aristolochia \\
Rosmarinic acid & Cordia Verbenaceae \\
Turmerin & Curcuma longa \\
Glycoproteins & Withaniasomnifera \\
Amides & Strychnosnux vomica \\
\hline
\end{tabular}


Table 2: Following plants are being used by traditional healers as a treatment towards snake bites.

\begin{tabular}{lll} 
Parts of plants used & Family & Plant \\
Whole plant & Avanthaceae & Andrographispaniculata \\
& Asteraceae & Eclipta alba \\
& Lamiaceae & Leucusaspera \\
& Leguminaceae & Mimosa pudica \\
Aerial parts & Punicaceae & Punicagranatum \\
& Loranthaceae & Viscumarticulatum \\
Stem & Bombaceae & Bombax ceiba \\
& Musaceae & Enseteedule \\
Stem bark & Moringaceae & Moreingaolifera \\
& Apocynaceae & Alstoniascholaris \\
Bark & Fabaceae & Derisscandens \\
Leaf & Rubiaceae & Butea monosperma \\
& Iridaceae & Allium cepa \\
& Liliaceae & Asparagus racemosus \\
Root & Bombaceae & Bombax ceiba \\
& Moringaceae & Moreingaolifera \\
Fuber & Leguminaceae & Cassia tora \\
Seeds & Solanaceae & Strychnosnux vomica \\
\hline
\end{tabular}

Table 3: List of Flavanoids\& their relevance in medical research. Wide range of medical applications can be found in this phyto-chemicals.

\begin{tabular}{ll} 
Flavonoid (Subclass) & Relevance in Medical Research \\
\hline Luteolins (Flavone) \&Apigenins & $\begin{array}{l}\text { Phytoestrogen with anti-inflammatory \& anti-bacterial functions, an inducer of } \\
\text { apoptosis }\end{array}$ \\
Cyanidins (Anthocyanidins) & Anti-cancer, Anti-oxidant, beneficial to eyes and nerves \\
Glycitein, Daidzein & Cardio-protective \\
Kaempferol (Flavonol) & Cardio-protective, anti-gastric cancer \\
Quercetins (Flavonol) & Cardio-protective, anti-gastric cancer \\
\hline
\end{tabular}

Table 4: Anthocyanin \& flavonoid contents in Brassica oleracea. All these Phyto-molecules have medicinal activities.

\begin{tabular}{ll} 
B. Oleracea Variety Verification & Anthocyanins (C-Cyanidin) \\
var.capitata.f.rubra & C-3-(caffeoyl)-(p-coumaroyl)-diglycoside-5-glycoside \\
var.capitata.f.rubra & C-3-(caffeoyl)-diglycoside-5-glycoside \\
var.capitata.f.rubra & C-3-(caffeoyl)-diglycoside-5-glycoside \\
B. oleracea Variety Verification & Flavonol (Q-Quercetin; K-Kaempferol) \\
var. acephala, var. botrytis Italica & Q-3-O-Sophorotrioside-7-O-sophoroside \\
var. acephala, var. botrytis Italica & Q-3-O-Sophorotrioside-7-O-glycoside \\
var. botrytis Italica & Q-3-O-glycosides \\
\hline
\end{tabular}




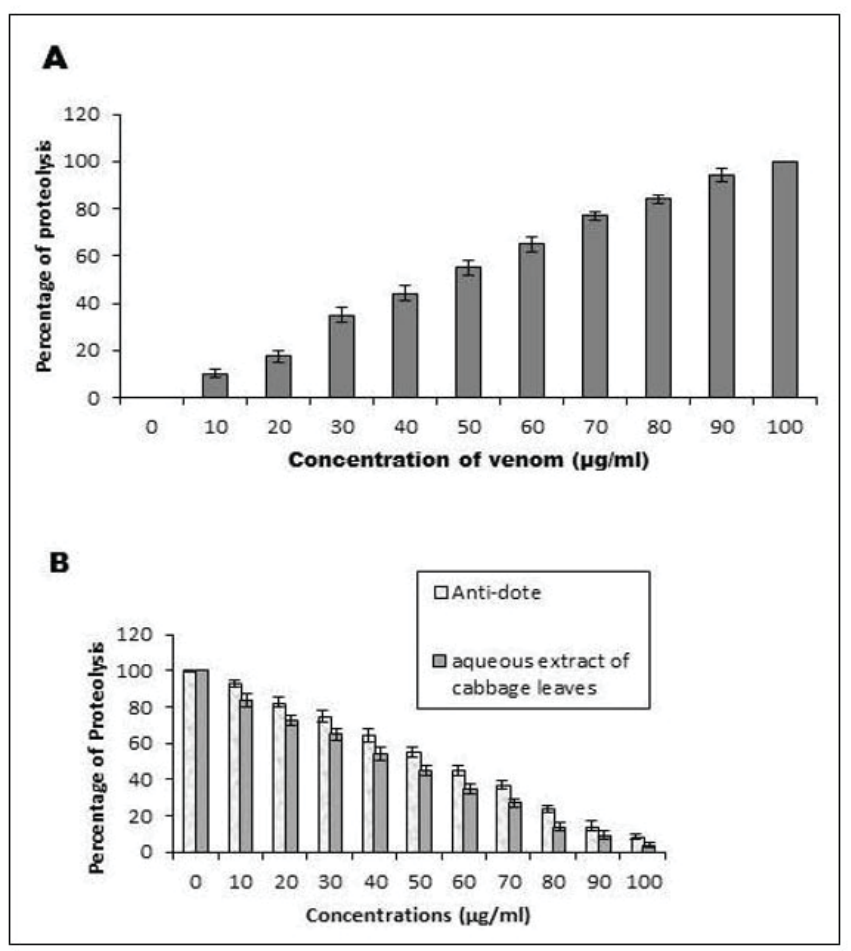

Figure 1: Effect of cabbage aqueous extracts and commercial Anti-dotes on proteolysis induced by Daboiarussellivenom. (A) Effective concentration $50\left(\mathrm{EC}_{50}\right)$ of Daboiarussellion goat's blood was determined at $40.54 \mathrm{micro}-\mathrm{g} / \mathrm{mL}$ after $100 \mathrm{mins}$ (B) Keeping the $\mathrm{EC}_{50}$ value constant for the snake venom, the percentage inhibition of proteolysis of goat's blood in the presence of the aqueous extract of cabbage and the commercial anti-dote was observed with the cabbage extract preventing hemolysis more efficiently than the commercially available anti-dote.

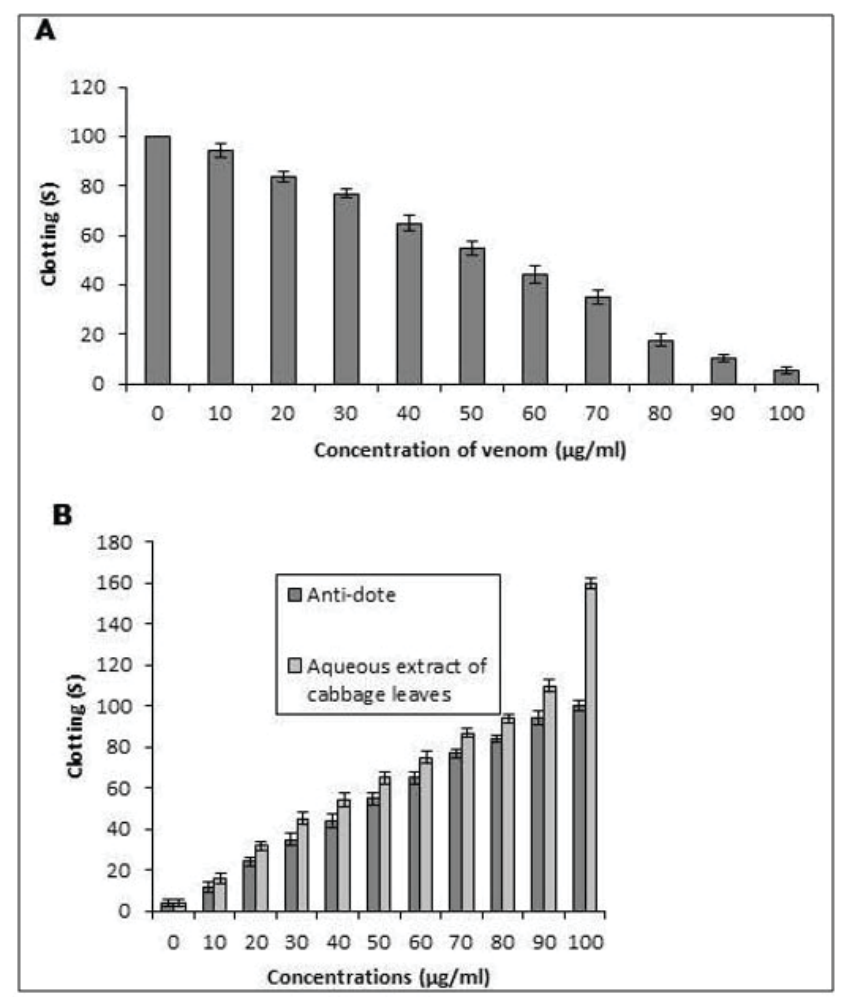

Figure 2: Effect of aqueous extract of cabbage on clotting induced by snake venom. (A) minimum coagulant dose (MCD) was calculated at $30.69 \mu \mathrm{g} / \mathrm{ml}$ for goat's plasma i.e. this amount coagulated the goat's plasma at $60 \mathrm{~s}$. Keeping this amount constant, the aqueous extracts of cabbage and the commercial anti-dote separately were kept at room temperature for 30 minutes with $1 \mathrm{MCD}$ of venom (30.69 micro $\mathrm{g} / \mathrm{mL}$ ) and then the mixture was added to the plasma to record the clotting time. The aqueous extract of cabbage showed higher preventive action than the commercial anti-dote by increasing the clotting time as compared to the control set. 